\title{
BMJ Open General practitioners' views of clinically led commissioning: cross-sectional survey in England
}

\author{
Valerie Moran, ${ }^{1}$ Kath Checkland, ${ }^{2}$ Anna Coleman, ${ }^{2}$ Sharon Spooner, ${ }^{3}$ \\ Jonathan Gibson, ${ }^{4}$ Matt Sutton ${ }^{4}$
}

To cite: Moran V, Checkland $\mathrm{K}$, Coleman A, et al. General practitioners' views of clinically led commissioning: cross-sectional survey in England. BMJ Open 2017;7:e015464. doi:10.1136/ bmjopen-2016-015464

- Prepublication history and additional material are published online only. To view please visit the journal online (http://dx.doi. org/10.1136/10.1136/bmjopen2016-015464).

Received 6 December 2016 Revised 30 March 2017 Accepted 21 April 2017

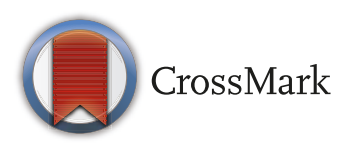

${ }^{1}$ Department of Health Services Research and Policy, London School of Hygiene \& Tropical Medicine, Tavistock Place, London, UK

${ }^{2}$ Division of Population Health, Health Services Research and Primary Care,University of Manchester, Manchester, UK ${ }^{3}$ NIHR School for Primary Care Research, University of Manchester, Manchester, UK

${ }^{4}$ Centre for Health Economics, University of Manchester, Manchester, UK

Correspondence to Dr Valerie Moran; valerie.moran@Ishtm.ac.uk

\section{ABSTRACT}

Objectives Involving general practitioners (GPS) in the commissioning/purchasing of services has been an important element in English health policy for many years. The Health and Social Care Act 2012 handed responsibility for commissioning of the majority of care for local populations to GP-led Clinical Commissioning Groups (CCGs). In this paper, we explore GP attitudes to involvement in commissioning and future intentions for engagement.

Design and setting Survey of a random sample of GPS across England in 2015.

Method The Eighth National GP Worklife Survey was distributed to GPs in spring 2015. Responses were received from 2611 respondents (response rate $=$ $46 \%$ ). We compared responses across different GP characteristics and conducted two sample tests of proportions to identify statistically significant differences in responses across groups. We also used multivariate logistic regression to identify the characteristics associated with wanting a formal CCG role in the future.

Results While GPs generally agree that they can add value to aspects of commissioning, only a minority feel that this is an important part of their role. Many current leaders intend to quit in the next 5 years, and there is limited appetite among those not currently in a formal role to take up such a role in the future. CCGs were set up as 'membership organisations' but only a minority of respondents reported feeling that they had 'ownership' of their local CCG and these were often GPs with formal CCG roles. However, respondents generally agree that the CCG has a legitimate role in influencing the work that they do. Conclusion CCGs need to engage in active succession planning to find the next generation of GP leaders. GPS believe that CCGs have a legitimate role in influencing their work, suggesting that there may be scope for CCGs to involve GPs more fully in roles short of formal leadership.

\section{INTRODUCTION}

Ever since the split between 'purchasing' and 'providing' care was introduced in the UK National Health Service (NHS) in 1990, successive UK governments have experimented with different ways of bringing the clinical knowledge and understanding of front-line general practitioners (GPs) into the commissioning process. GP fundholding,
Strengths and limitations of this study

This paper is the first to present the views of a national sample of general practitioners (GPs) on clinically led commissioning from a survey that took place in 2015, 3 years following the establishment of Clinically Commissioning Groups (CCGs).

- Inclusion of GPs both with and without formal CCG roles allows comparison of views and future intentions and sampling was not restricted according to any regional or CCG boundaries.

- The survey sample contains a slightly higher proportion of older and male GPs than the GP population as a whole while salaried GPs and locums are relatively under-represented.

- The study data focuses on a range of GPs' views and beliefs about CCG work but is unable to elucidate how responses may have been influenced by local experience of CCG effectiveness or how individual GPs' motives for undertaking CCG work was reflected in their intention for future participation.

- The survey findings represent a snapshot in time. The policy context in England is changing rapidly, and the views of GPs may be affected by these changes.

total purchasing pilots, primary care groups and practice-based commissioning were all designed to give GPs a role in decisions about the services that their patients would receive. The UK has not been alone in developing such initiatives, with jurisdictions as diverse as Estonia, Italy, Finland and Spain experimenting with some forms of GP-led purchasing of care. ${ }^{1}$ However, the NHS in England has gone further than other health system in this direction.

The 2012 Health and Social Care Act embedded the concept of clinically led commissioning more firmly, replacing managerially led purchasing organisations-primary care trusts-with GP-led Clinical Commissioning Groups (CCGs). These groups are constituted as 'membership organisations', with every GP practice required 
to be a member of their local group and contribute to its work. CCGs were initially given responsibility for commissioning emergency and elective hospital care, as well as community services such as district nursing and community rehabilitation. Subsequent further system change has also given them responsibility for commissioning primary care services from their members.

The rationale behind the new system was set out in the 2010 White Paper, 'Equity and Excellence'"2:

The Government's reforms will liberate professionals and providers from top-down control. This is the only way to secure the quality, innovation and productivity needed to improve outcomes. We will give responsibility for commissioning and budgets to groups of GP practices; and providers will be freed from government control to shape their services around the needs and choices of patients. (2: para 4.1)

Thus, it was argued that front-line professionals have both knowledge of what is required for patients and capacity to innovatively develop services, which together enable improvement in service quality.

It is possible to engage GPs in commissioning care, and that they can, in the right circumstances, innovate and improve aspects of care. ${ }^{3}$ However, GP commissioners have not addressed broader population health challenges and previous GP commissioning initiatives have not saved money or reduced costs. Furthermore, clinically led commissioning brings with it significant transaction costs and opportunity costs associated with taking GPs away from their front-line roles. ${ }^{3}$ In spite of this rather mixed evidence and in the teeth of considerable opposition, ${ }^{4}$ the coalition government pushed ahead, formally establishing CCGs in April 2012.

CCG constitutions vary, but all have established a governing body, led by a chair and an accountable officer. These can be clinicians or non-clinicians, but most also have representation from a range of local GPs and have established locality and membership meetings to which practices must send a representative. ${ }^{5}$ Participation in CCG work requires significant time commitment for GP practices, and concerns have been raised about sustainability. ${ }^{6-8}$ Ongoing clinical involvement in the longer term will require the development of a new generation of local GP leaders who are prepared to take time out from other duties to take on this additional workload. Furthermore, as the composition of the GP workforce alters due to an increase in the number of salaried GPs relative to the number of GP partners, CCGs will increasingly need to recruit leaders and governing body members from a broader range of GPs.

Previous research ${ }^{9}$ has suggested that the development of CCGs has enabled the potential involvement of a greater number of GPs in commissioning processes. However, this research also highlighted the need for CCGs '...to actively consider the needs of their membership, and design systems to bring in as wide a variety of voices as possible'. ${ }^{9}$ Methods of communication were also an issue; CCGs which used multiple modes of communication and those which were more proactive in encouraging the involvement of a diverse range of GPs were most successful in engaging their members. Furthermore, many CCGs have put in place governance structures which elect or select GP leaders for finite terms. ${ }^{10}$ There is some evidence that, compared with the whole GP workforce, CCG leaders are more likely to be male, and less likely to be salaried GPs. Taken together, this suggests that CCGs will need to put in place active succession plans if they are to be representative groups and able to maintain clinical leadership in the longer term.

Against this background, we conducted a National GP Worklife Survey in spring 2015. This survey has been carried out by the University of Manchester eight times since 1998, asking questions about GP workload, job satisfaction and sources of pressure ${ }^{11}$ (http://research.bmh. manchester.ac.uk/healtheconomics/research/reports). Since 2010, questions have also been asked about attitudes to clinically led commissioning, including current involvement, understandings and beliefs about the role of GPs as commissioners and about intentions to become involved in the future. In order to allow comparisons, some questions used in the survey are derived from a similar survey carried out by the Nuffield Trust. ${ }^{12}$ In this paper, we present the findings from this part of the survey for 2015 (the most recent year available) and explore what it tells us about the sustainability of clinically led commissioning in the English NHS.

\section{METHODS}

\section{Data and statistical analysis}

We used data from the Eighth National GP Worklife Survey ${ }^{13}$ which was collected by the University of Manchester between March and May 2015. The target sample consisted of GP partners, salaried GPs (including GP retainers) and GP locums practising in England. GPs were invited to supply data using a paper questionnaire or they could choose to complete it online (148 took this option, representing $2.6 \%$ of the total target sample of 5659 GPs). The survey consists of two samples: a random cross-sectional sample of practising GPs and a longitudinal sample of practising GPs who responded to the previous survey in 2012.

For this paper, we use responses from the total pooled sample of 2611 respondents. This represents an overall response rate of $46 \%$. Of the total pooled sample, 1439 $(55 \%)$ came from the longitudinal sample only, 1035 $(40 \%)$ came from the cross-sectional element only, while $137(5 \%)$ were part of both the cross-sectional and longitudinal samples. We cleaned the data to remove five observations where the respondent reported their age as under 20 years or over 83 years, 43 observations where the respondent reported they were both a partner and a salaried or locum GP and 19 observations where the respondent did not record their contract type. This resulted in a sample of 2544 respondents. 
The 2015 Survey contained a number of questions on respondents' opinions on clinical commissioning and knowledge of and engagement with their CCG, with the wording of some of the questions drawing on a local survey carried out by the Nuffield Trust. ${ }^{12}$ This section of the questionnaire is available in online supplementary appendix 1 . These questions were rated on ordinal scales with 1 representing' strongly disagree' or 'decrease a lot' and 5 representing 'strongly agree' or 'increase a lot'. We constructed binary variables equal to 1 if a respondent rated a question 4 or 5 (agree/strongly agree or increase a little/a lot) and equal to 0 if a respondent rated a question 1 or 2 (strongly disagree/disagree or decrease a lot/little). Respondents who rated a question 3 (neither agree nor disagree; no change; neutral) were omitted from these binary variables.

We compared responses across different characteristics including age (under 50 years, 50 years and over), gender, formal role in CCG and GP partners versus salaried or locum GPs. We conducted two sample tests of proportions to identify statistically significant differences in responses across groups.

We also used multivariate logistic regression to identify the characteristics associated with wanting a formal CCG role in the future. We chose a logit model as we have a binary dependent or response variable that is constrained to take on values of 0 and 1 . The logistic regression shows how the probability of a value of 1 depends on the set of independent or control variables. We coded the dependent variable in the logit model as 1 for respondents who would like a formal role in the future $(n=172)$ and 0 for respondents who said they did not want or did not know if they wanted a future formal role $(n=2291)$. Independent variables included demographic information such as age, gender, ethnicity and marital status; whether the GP was a partner in the practice; and whether the GP undertook additional work either within or outside the NHS. In order to investigate whether GPs currently with a formal CCG role were more likely to report wanting a future formal CCG role, we included a dummy variable equal to 1 if the GP currently has a formal CCG role. We also interacted this variable with the other independent variables. We constructed a variable to measure a respondent's knowledge of and engagement with their CCG that reflected the average response over the eight questions measuring knowledge of and engagement with the CCG (see online supplementary appendix 1). We report results as marginal effects, which show the association between the independent variables and the probability of reporting to want a future formal CCG role. Separate marginal effects are not estimated for the interaction variables as the value of the interaction variable cannot change independently of the values of the constituent variables. ${ }^{14}$ All analyses were conducted in Stata V. $14 .^{15}$

\section{RESULTS}

\section{Sample characteristics}

The majority $(n=2265,89 \%)$ of respondents were GP partners. Ten per cent $(n=258)$ of respondents were salaried GPs only, while the remaining $1 \%$ of respondents were locum GPs only $(n=8)$ or salaried and locum GPs $(n=13)$. Data from NHS Digital indicate that $73 \%$ of GPs in England in 2014 were partners or practice owners and $27 \%$ were salaried or locum GPs (http://digital.nhs. uk/catalogue/PUB20503). Thus, our sample contains a higher proportion of partner GPs than in the workforce as a whole.

Over half $(53 \%)$ of respondents were male. Just under half $(43 \%)$ were aged $28-49$ years. This compares with a national workforce figure in 2014 of $48.1 \%$ male GPs (including salaried and partners but excluding locums) and $60 \%$ aged under 50 (NHS Digital http://digital.nhs. uk/catalogue/PUB20503). Thus, both male GPs and GPs aged 50 years and over are slightly over-represented in our respondents compared with national figures.

Two hundred and eighty-nine $(11 \%)$ of the survey respondents reported having a formal role in the CCG such as office holder, committee member or work stream lead. Those with formal roles within the CCG were more likely to be male $(69 \%$ vs $52 \%), 50$ years and over $(66 \%$ vs $55 \%)$ and be a GP partner within their practice $(95 \%$ vs $88 \%$ ) compared with those with no formal role. GP partners are more likely than salaried/locum GPs to be male ( $57 \%$ vs $21 \%$ ), aged 50 years and over ( $59 \%$ vs $26 \%$ ), and to have a formal CCG role ( $12 \%$ vs $6 \%)$.

\section{Opinions on the added value and legitimate roles of GPs in clinical commissioning}

We asked GPs about the extent to which they viewed commissioning as part of their GP role. $29.9 \%$ agreed or strongly agreed that commissioning was part of their role, while $46.5 \%$ disagreed or strongly disagreed that commissioning was part of their role. We also asked respondents to indicate how much GPs could add value to various aspects of commissioning work. More than half of the respondents agreed that GPs could add value to needs assessment, pathway design and contract negotiation (figure 1).

GPs with a formal CCG role were significantly more likely than GPs without a formal CCG role to view clinical commissioning as a legitimate part of their overall role as a GP $(80 \%$ vs $33 \%$; $\mathrm{p}<0.001)$. Males were more likely than females to agree that commissioning was part of their GP role $(42 \%$ vs $35 \%, \mathrm{p}=0.001)$.

Respondents with a formal CCG role were more likely than respondents with no formal CCG role to agree or strongly agree that GPs added value to each of four broad aspects of commissioning listed in the survey (figure 2). Female respondents were more likely than male respondents to agree or strongly agree that GPs added value to all these aspects of commissioning.

We asked respondents to indicate the extent to which CCGs should have an influence over each of seven issues related to GP working patterns, patient access and GPs' 


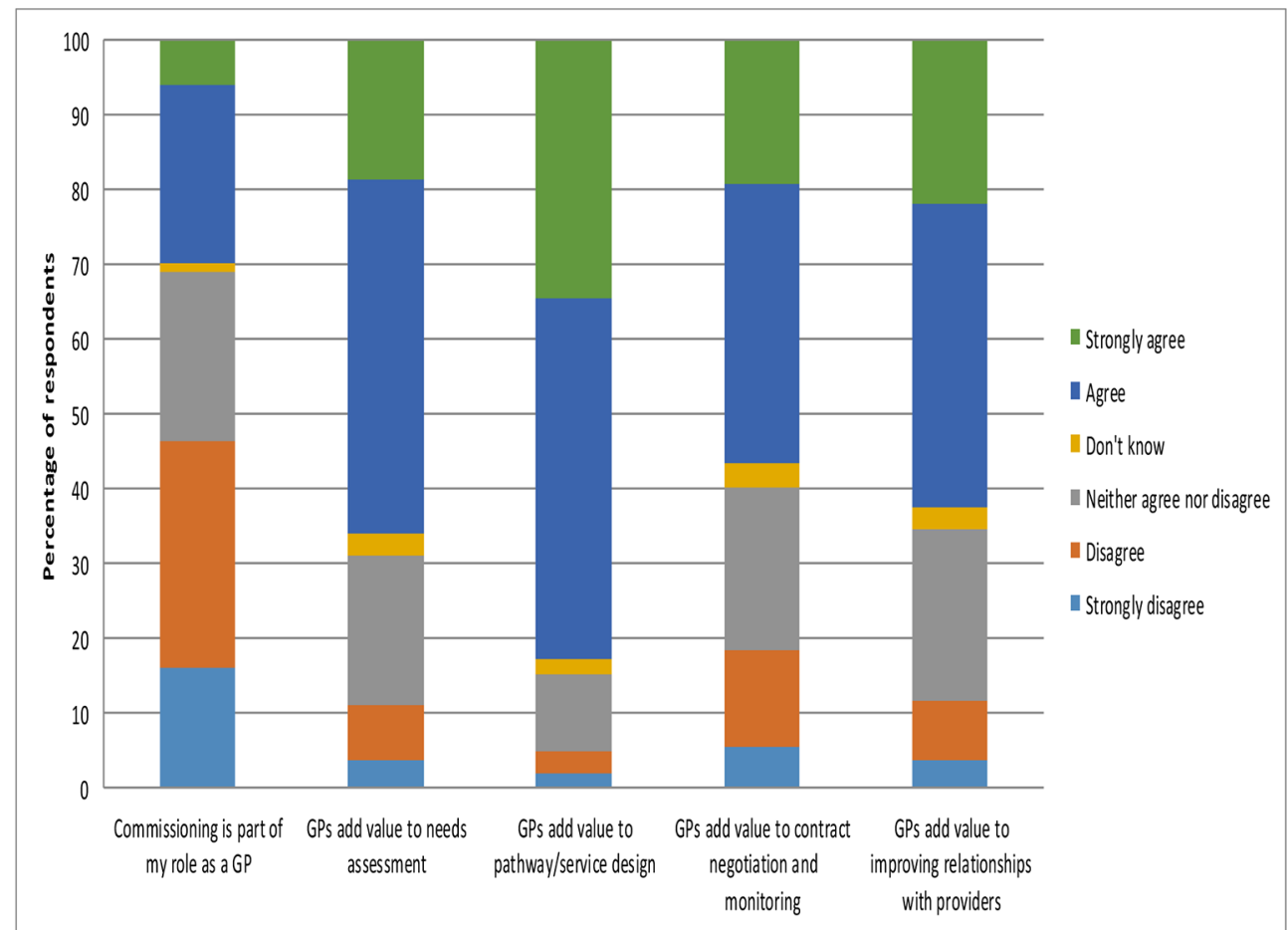

$\mathrm{N}=2,520$ to 2,526 .

Figure 1 Views of the role of general practitioners (GPs) in commissioning.

contract issues. GPs with a formal CCG role were significantly more likely than GPs with no formal role to think that CCGs should have an influence over prescribing (93\% vs $76 \%, \mathrm{p}<0.001$ ), patient use of accident and emergency
(A\&E) and walk-in centres (84\% vs $68 \%, \mathrm{p}<0.001)$, referrals made $(82 \%$ vs $51 \%, \mathrm{p}<0.001)$, quality of care $(82 \%$ vs $73 \%, \mathrm{p}=0.005)$ and practice opening hours $(41 \%$ vs $24 \%$, $\mathrm{p}<0.001)$. The differences between GPs with a formal role

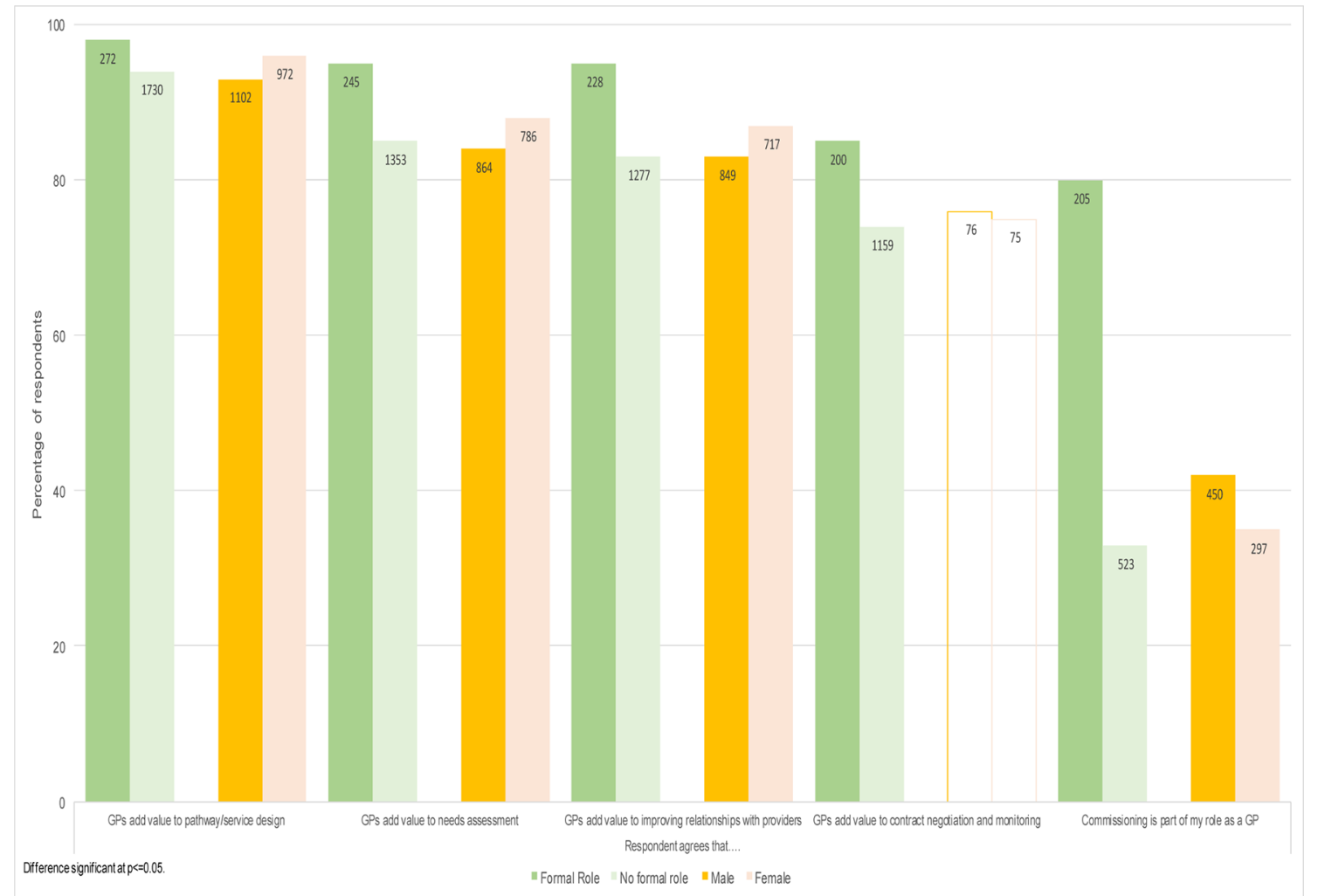

Figure 2 Role of general practitioners (GPs) in commissioning-opinions split by role and gender, percentage and sample size, significant differences only shown (5\% level). 


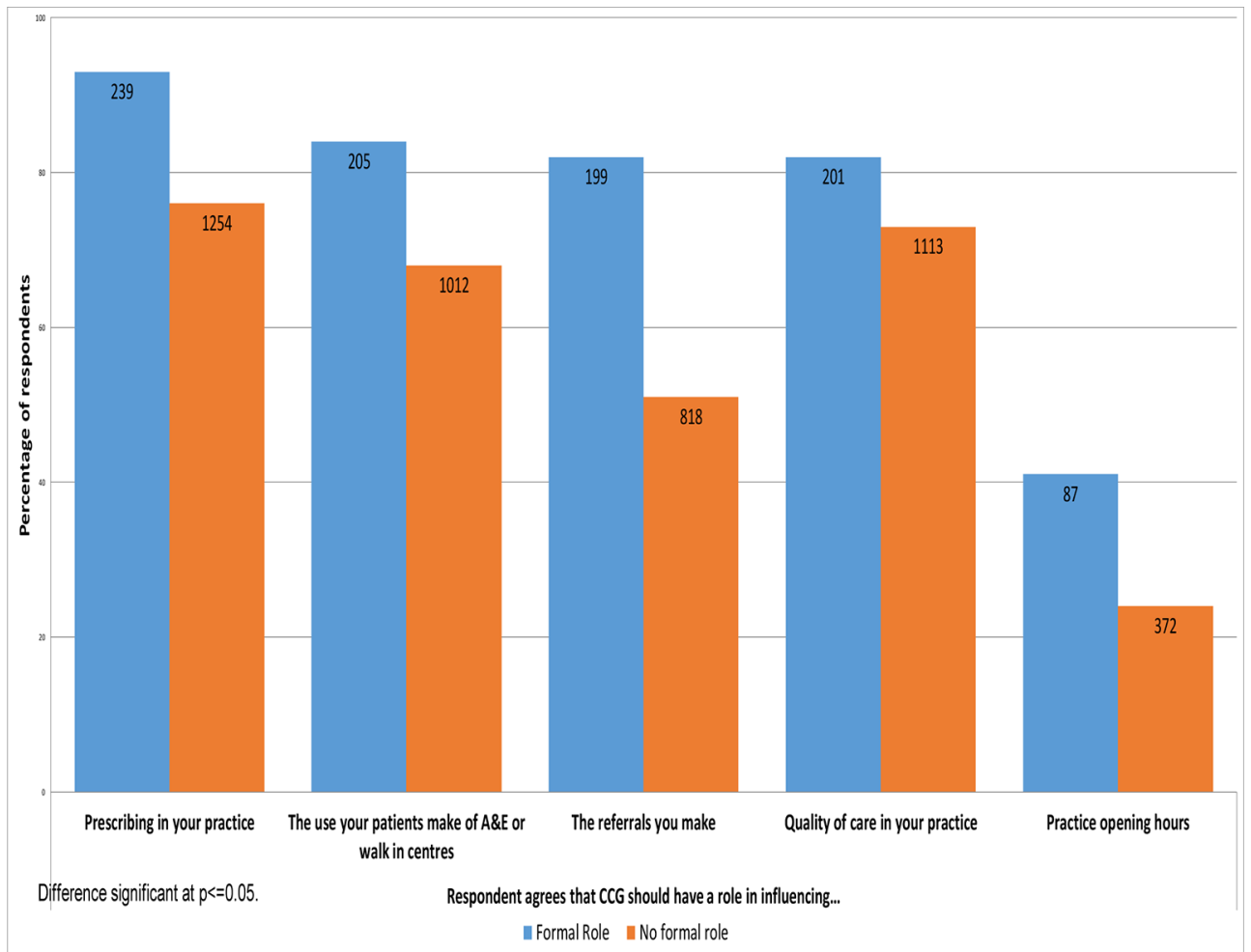

Figure 3 Views of general practitioners with and without formal CCG roles on the role of CCGs, percentage and sample size. CCG, Clinically Commissioning Group.

and those with no formal role were not statistically significant for influencing practice contracts $(64 \%$ vs $57 \%$, $\mathrm{p}=0.05)$ or the management of poor GP performance $(72 \%$ vs $76 \%, \mathrm{p}=0.167)$.

GPs with no formal role in their CCG seemed more comfortable with the CCG influencing their prescribing behaviour than their referrals or their practice opening hours (figure 3).

\section{Current engagement with CCGs}

We asked respondents about their relationship with their CCG as reflected in areas such as feeling informed, represented, in contact, influential and included. Fortyfive per cent reported feeling informed about what the CCG was trying to achieve (figure 4). Thirteen per cent of respondents agreed that the decisions made by their CCG reflected their views. Sixteen per cent of respondents felt that the CCG was 'owned' by its members. Nearly one-third (31\%) of respondents felt that they could influence the CCG if they wanted to.

We found significant differences between respondents with different characteristics. Levels of knowledge of and engagement with their CCG showed some variation across

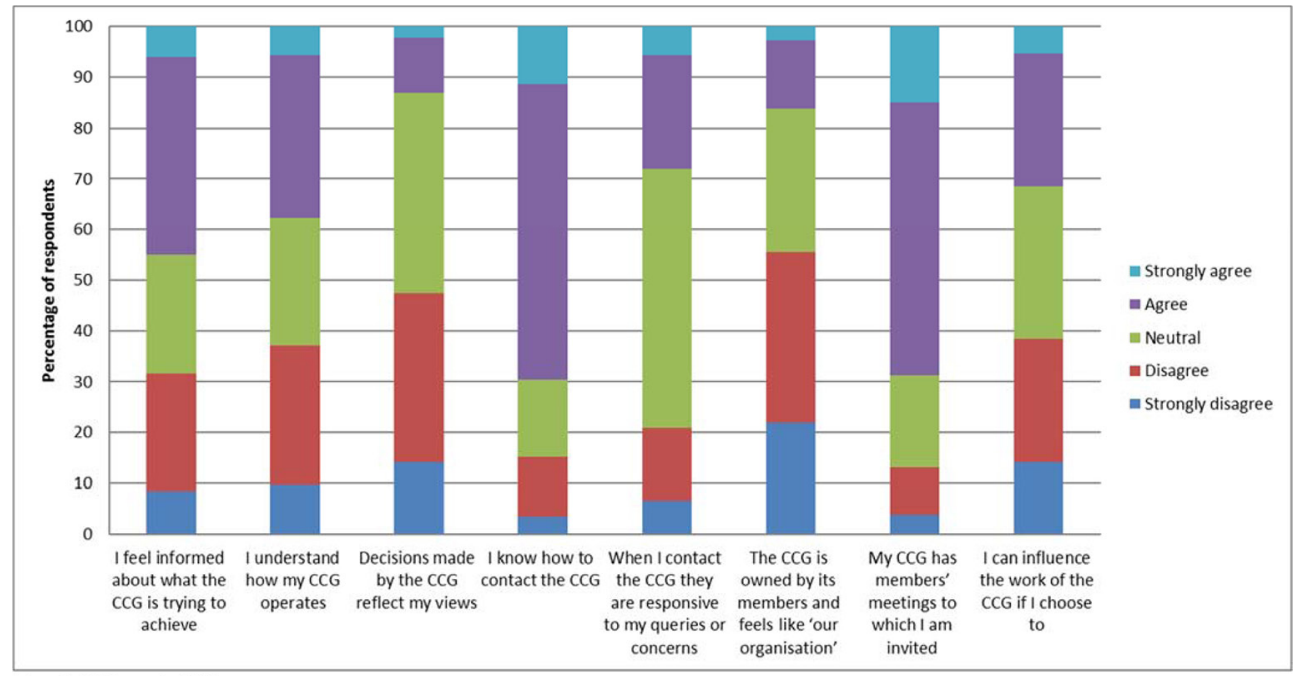

$\mathrm{N}=2,505$ to 2,517

Figure 4 General practitioners' knowledge of and engagement with their CCG. CCG, Clinically Commissioning Group. 
Table 1 General practitioners' knowledge of and engagement with CCG, by role, gender, contract and age

\begin{tabular}{|c|c|c|c|}
\hline Respondent agrees that: & $\begin{array}{l}\text { Formal role (number } \\
\text { agreeing) }\end{array}$ & $\begin{array}{l}\text { No formal role } \\
\text { (number agreeing) }\end{array}$ & $\begin{array}{l}\text { Difference } \\
\text { ( } p \text { value) }\end{array}$ \\
\hline I feel informed about what the CCG is trying to achieve & $0.87(222)$ & $0.55(858)$ & $0.33(p<0.001)$ \\
\hline I understand how my CCG operates & $0.85(215)$ & $0.45(692)$ & $0.40(p<0.001)$ \\
\hline Decisions made by the CCG reflect my views & $0.72(150)$ & $0.14(173)$ & $0.58(p<0.001)$ \\
\hline I know how to contact the CCG & $0.99(274)$ & $0.79(1392)$ & $0.20(p<0.001)$ \\
\hline $\begin{array}{l}\text { When I contact the CCG they are responsive to my queries } \\
\text { or concerns }\end{array}$ & $0.87(189)$ & $0.50(474)$ & $0.37(p<0.001)$ \\
\hline $\begin{array}{l}\text { The CCG is owned by its members and feels like 'our } \\
\text { organisation' }\end{array}$ & $0.58(131)$ & $0.18(266)$ & $0.40(p<0.001)$ \\
\hline My CCG has members' meetings to which I am invited & $0.96(261)$ & $0.82(1380)$ & $0.14(p<0.001)$ \\
\hline \multirow[t]{2}{*}{ I can influence the work of the CCG if I choose to } & $0.80(195)$ & $0.40(565)$ & $0.40(p<0.001)$ \\
\hline & Male (n) & Female (n) & $\begin{array}{l}\text { Difference } \\
\text { ( } p \text { value) }\end{array}$ \\
\hline I understand how my CCG operates & $0.54(554)$ & $0.45(385)$ & $0.09(p<0.001)$ \\
\hline Decisions made by the CCG reflect my views & $0.24(210)$ & $0.18(120)$ & $0.06(0.006)$ \\
\hline I know how to contact the CCG & $0.86(964)$ & $0.78(771)$ & $0.06(p<0.001)$ \\
\hline \multirow[t]{2}{*}{ My CCG has members' meetings to which I am invited } & $0.86(959)$ & $0.82(748)$ & $0.04(0.009)$ \\
\hline & Partner (n) & Salaried/locum (n) & $\begin{array}{l}\text { Difference } \\
\text { ( } p \text { value) }\end{array}$ \\
\hline I feel informed about what the CCG is trying to achieve & $0.61(1049)$ & $0.40(82)$ & $0.21(p<0.001)$ \\
\hline I understand how my CCG operates & $0.53(892)$ & $0.28(55)$ & $0.25(p<0.001)$ \\
\hline I know how to contact the CCG & $0.85(1622)$ & $0.57(129)$ & $0.28(p<0.001)$ \\
\hline $\begin{array}{l}\text { When I contact the CCG they are responsive to my queries } \\
\text { or concerns }\end{array}$ & $0.58(658)$ & $0.41(34)$ & $0.17(0.003)$ \\
\hline My CCG has members' meetings to which I am invited & $0.87(1625)$ & $0.52(95)$ & $0.35(p<0.001)$ \\
\hline \multirow[t]{2}{*}{ I can influence the work of the CCG if I choose to } & $0.46(731)$ & $0.36(59)$ & $0.10(0.021)$ \\
\hline & Under 50 (n) & 50 years and over $(n)$ & $\begin{array}{l}\text { Difference } \\
\text { (p value) }\end{array}$ \\
\hline I understand how my CCG operates & $0.47(376)$ & $0.53(559)$ & $-0.06(0.009)$ \\
\hline I know how to contact the CCG & $0.79(728)$ & $0.84(996)$ & $-0.05(0.001)$ \\
\hline My CCG has members' meetings to which I am invited & $0.80(684)$ & $0.86(1012)$ & $-0.06(p<0.001)$ \\
\hline
\end{tabular}

CCG, Clinically Commissioning Group.

subgroups but, as indicated, were reported at significantly higher levels by GPs who had a formal CCG role, were male, GP partners and aged 50 years and over (see table 1). As might be expected, those with a formal role in the CCG were significantly more likely to feel engaged and informed. Thus, for example, while $72 \%$ of those with a formal role felt that decisions reflected their views, only $14 \%$ of GPs without a role did so. Furthermore, even those with a formal role appeared to feel that CCGs were struggling to become truly 'membership organisations', with only $58 \%$ of those with a formal role and $18 \%$ of those without agreeing that their CCG was 'owned' by its members.

Future intentions regarding a formal CCG role

Of the 289 respondents with a current formal role in the CCG, almost half $(49 \%, \mathrm{n}=141)$ intended to quit this role in the next 5 years. Of the 2129 respondents who currently do not have a formal CCG role, only $3 \%(\mathrm{n}=64)$ said they would like such a role in the future. Eighty-nine per cent $(n=1886)$ said they would not like a formal role in the future and $7 \%(\mathrm{n}=153)$ were undecided.

We undertook a complete case analysis for the logistic regression. The estimation sample was reduced to 1734 due to missing data for the dependent and independent variables.

Table 2 displays the mean value of the variables included in the logit regression and the estimates expressed as marginal effects.

In the reduced estimation sample, $10 \%$ of respondents had a formal CCG role. Just over half were aged 50 years and over $(55 \%)$ and male $(53 \%)$. The majority $(85 \%)$ were of white ethnicity, married or cohabiting 
Table 2 Logit regression of wanting a CCG role in the future on respondent characteristics

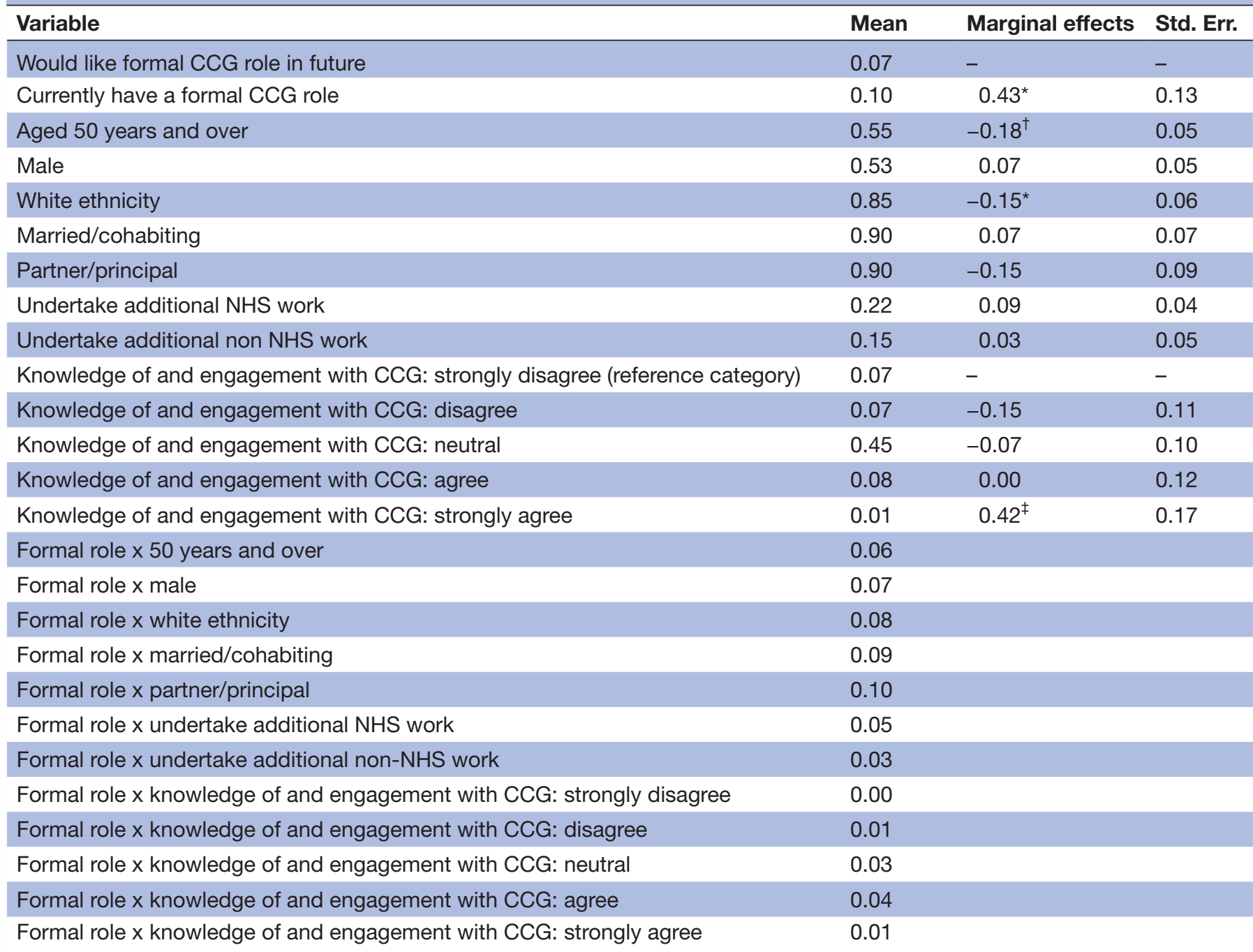

$\mathrm{n}, 1734$.

${ }^{*} p<0.01$.

$\mathrm{tp}<0.001$.

$\neq \mathrm{p}<0.05$.

CCG, Clinically Commissioning Group; NHS, National Health Service.

$(90 \%)$ and were a GP partner/principal $(90 \%)$. Around one-fifth (22\%) undertook additional employed work for the NHS. This could include additional more specialised work, sessions in a hospital or community facility. Less than one-fifth $(15 \%)$ undertook additional employed work outside the NHS such as academic research, private practice, and so on.

Considering the interaction variables, $6 \%$ of the estimation sample had a formal CCG role, and were aged 50 years or older, while $7 \%$ were male and had a formal role. Those with a formal role and of white ethnicity comprised $8 \%$ of the estimation sample, while $9 \%$ had a formal role and were married. One-tenth of the estimation sample had a formal CCG role and were a GP partner. Only $3 \%-5 \%$ had a formal CCG role and undertook additional work within or outside the NHS. None of the interaction variables were statistically significant in the logit regression.
Currently having a formal CCG role was associated with a 43 percentage point increased probability of reporting to want a future role. Similarly, a higher level of knowledge of and engagement with the CCG was associated with an increase of 42 percentage points in the probability of reporting to want a role in the future. Conversely, being 50 years of age or over was associated with an 18 percentage point reduction in the probability of reporting to want a future role. White ethnicity was associated with a 15 percentage point reduced probability of reporting to want a future role.

\section{DISCUSSION}

\section{Summary of findings}

We found that, after many decades of initiatives designed to involve GPs in the commissioning of healthcare, only $30 \%$ of respondents agreed that commissioning was 
part of their role. Male GPs and GP partners were more likely to agree that commissioning was part of their role, reflecting what is known about the make-up of CCG governing bodies. ${ }^{5}$ However, most did agree that GPs can add value to aspects of the commissioning process. In terms of the role of CCGs in influencing the work of practices, respondents were more comfortable with their CCG influencing their prescribing behaviour than their referrals or their practice opening hours. This may have implications for continued engagement and role acceptability as CCGs take over responsibility for commissioning primary care services. ${ }^{16}$

GPs with no formal role in their CCG report a relatively low level of understanding or engagement, with only $14 \%$ of 'rank and file' GPs reporting that their CCG's decisions represent their views, and $18 \%$ reporting that they feel any 'ownership' of their CCG. This suggests that the constitution of CCGs as 'membership organisations' has not been realised in practice. Male GPs, GP partners and older GPs currently report greater knowledge about and engagement with their CCG. Around half $(n=141)$ of those with formal roles in their CCG intend to quit in the next 5 years. Only $3 \%(n=64)$ of respondents with no current role reported wanting to take up such a role in the future. GPs of white ethnicity and older GPs were less likely to want a formal CCG role in the future.

\section{Strengths and limitations}

This survey took place in 2015 and therefore reports the views of a national sample of GPs after CCGs have been established for 3 years. The survey sample contains a slightly higher proportion of older and male GPs than the GP population as a whole. Salaried GPs and locums are relatively under-represented which may be attributed to difficulty in locating or contacting them due to more frequent changes in their workplaces. Inclusion of GPs who both have and do not have formal roles in CCGs allows comparison of their views and future intentions, and sampling was not restricted according to any regional or CCG boundaries. Data from this study focused on a range of GPs' views and beliefs about CCG work but are unable to elucidate how their responses may have been shaped by local experience of CCG effectiveness (eg, in achieving service improvement or shifting priorities) or how individual GPs' motives for undertaking CCG work was reflected in their intention for future participation. In addition, the role of CCGs continues to develop rapidly, and the overall landscape of the NHS is changing at a similar pace following the publication of the Five Year Forward View, setting out a vision for new models of care delivery. ${ }^{17}$ Thus, our findings only represent a snapshot of GP views at a particular moment in time.

\section{Unanswered questions}

The quantitative nature of the data precludes insights into factors influencing GPs' views and responses, for example, the perceived performance of individual CCGs. We are also unable to explore GPs' motivation for current and future CCG involvement, and how the leadership styles of GPs who are actively engaged in CCG work impacts on the likelihood of other GPs following this path. These questions could be explored in a future qualitative analysis. Future work could also exploit the longitudinal nature of the survey data to provide insights into how responses have evolved over time. The survey includes a question on whether the respondent's practice is part of a GP Federation. With increasing coverage and development of GP Federations over time, it would be interesting to consider whether they have an impact on the willingness of GPs to engage in commissioning duties. Future iterations of the survey could elicit information on the geographical location of the practice in order to investigate if there are any significant regional variations in the attitudes of GPs to commissioning responsibilities.

\section{Comparison with existing literature}

Research by the Nuffield Trust and the Kings Fund has been tracking GP views in six CCGs for a number of years. ${ }^{12}{ }^{18}$ In 2016, their survey suggested that, in their study CCGs, just over half felt engaged in the work of the CCG, and $20 \%$ felt that they could influence the work of the CCG. This is somewhat lower than the $31 \%$ of our respondents who felt able to influence the work of their CCG. Similarly, 38\% of the Nuffield/Kings Fund respondents felt well informed about their CCG's work, compared with $45 \%$ of respondents to this question in our study. However, 23\% of respondents in the Nuffield/ Kings Fund study reported feeling a degree of 'ownership' of their CCG, compared with $16 \%$ in our study. In addition, they report a greater proportion of current CCG leaders wishing to remain in their current roles $(70 \%)$, with $11 \%$ of those currently not involved suggesting they might like to do so in the future.

Our own research has previously documented a preponderance of male GPs in leadership roles, ${ }^{5}$ and this is confirmed by other informal surveys (http:// www.pulsetoday.co.uk/women-hold-just-a-fifth-of-gp-positions-on-ccg-boards/14283550.article). Furthermore, research suggests that GPs vary in their enthusiasm for commissioning, and that these preferences are durable, with many of those who have engaged with CCGs also having a history of involvement with previous forms of clinically led commissioning. ${ }^{5}{ }^{19}$ Research on previous iterations of clinically led commissioning suggests that high degrees of engagement may be less important than an overall belief that the commissioning organisation has legitimacy. ${ }^{20}$ This may be encouraging for CCGs, given the fact that the majority of our respondents agreed that CCGs should have some role in influencing the work that they do in their practices and that more than half felt well informed about the CCG's aims.

\section{Implications for research and/or practice}

CCGs were at the centre of one of the largest reorganisations that the NHS has ever seen. ${ }^{4}$ They were created in order to cement the role of GPs in the commissioning of 
services, with policy makers claiming that clinical leadership would significantly improve the performance of the NHS. ${ }^{21}$ The two defining characteristics of CCGs which differentiate them from their managerially led predecessor organisations (primary care trusts) are as follows: their constitution as 'membership organisations', with GP practices established as members, and the leadership role assigned to GPs in their governance structures. ${ }^{22}$ Our research suggests that, 3 years after their establishment in shadow form, 'rank and file' GPs do not feel 'ownership' of their CCG, and feel themselves to have limited ability to influence its work. However, there is a consensus that GPs have something to offer the commissioning process.

In terms of GP leadership, there is also some cause for concern. If our findings are a true reflection of the wider population of CCG leaders, then it is likely that a significant proportion will leave their leadership roles in the next 5 years, and there is little evidence of a groundswell of enthusiasm to replace them. Furthermore, it is well documented that CCG leadership is dominated by men and by GP partners. As the GP workforce becomes increasingly feminised ${ }^{2324}$ and as more GPs choose salaried work (http://www.hscic.gov.uk/catalogue/PUB13849), it is important that CCGs actively recruit the next generation of leaders from beyond the 'usual suspects'.

Taken together, our findings point to a number of strategies that CCGs could consider as they prepare for the future. First, while GPs do not report high levels of engagement with their CCG, they do appear to feel that its involvement in aspects of their work is legitimate. Good working relationships between CCGs and member practices will be increasingly important as CCGs take over responsibility for commissioning primary care, and it is possible that greater engagement over resources, performance and quality management may provide an opportunity for CCGs to make themselves more relevant to GPs under pressure. If this is to be successful, then CCGs should consider carefully the ways in which they engage with practices and the approach that they take to commissioning them.

Second, our evidence has delineated the profile of those likely to seek CCG office in the future-those who already have a formal role in the CCG and those who feel more engaged with and knowledgeable about the CCG. If CCG governing bodies are to reflect the workforce better, it is important that governing bodies take note of their current membership profile and actively recruit new members from those currently not represented. In addition, our finding that even those who are relatively disengaged from the work of the CCG continue to believe that GPs can add value to the commissioning process suggests that CCGs might be successful in engaging a broader range of GPs in roles short of a formal leadership position. Targeting individuals and engaging them in smaller pieces of work that they see as relevant may be a route to more formal and longer-term involvement. In addition, actively engaging GPs in training to prepare them for CCG work may be of value.
Acknowledgements The survey formed part of the work programme of the Policy Research Unit on Commissioning and the Healthcare System (PRUComm) during 2015. The authors are grateful to all general practitioners who took time to complete the survey.

Contributors KC, MS, JG and AC designed the study. KC MS and JG were involved in the design of the questionnaire and $\mathrm{AC}$ was involved in designing the specific questions relating to findings reported here. VM analysed the data, with help from JG. VM, KC, AC and SS were involved in the interpretation of results and the initial drafting of the manuscript. VM and AC finalised the manuscript. JG and MS were involved in data collection and analysis and made substantial critical comments on the manuscript.

Funding The Policy Research Unit in Commissioning and the Healthcare System (PRUComm) is funded by the Department of Health Policy Research Programme.

Disclaimer The views expressed here represent those of the researchers, and not the Department of Health.

Competing interests VM, KC, JG, MS and AC received grant funding from the Department of Health via its Policy Research Programme for this research.

Patient consent No patients involved in study.

Provenance and peer review Not commissioned; externally peer reviewed.

Open Access This is an Open Access article distributed in accordance with the Creative Commons Attribution Non Commercial (CC BY-NC 4.0) license, which permits others to distribute, remix, adapt, build upon this work non-commercially, and license their derivative works on different terms, provided the original work is properly cited and the use is non-commercial. See: http://creativecommons.org/ licenses/by-nc/4.0/

C Article author(s) (or their employer(s) unless otherwise stated in the text of the article) 2017. All rights reserved. No commercial use is permitted unless otherwise expressly granted.

\section{REFERENCES}

1. Saltman RB, Rico A, Boerma WG, eds. Primary care in the driving seat? organizational reform in european primary care. Maidenhead, Berks: Open University Press, 2006.

2. Department of Health. Equity and excellence: liberating the NHS. London: The Stationary Office, 2010.

3. Miller R, Peckham S, Coleman A, et al. What happens when GPs engage in commissioning? two decades of experience in the English NHS. J Health Serv Res Policy 2016;21:126-33. http://hsr.sagepub. com/content/early/2015/07/08/1355819615594825.abstract

4. Timmins N. Never again? the story of the Health and Social Care Act 2012. A study in coalition government and policy making. London: The King's Fund, 2012.

5. Checkland K, Coleman A, Segar J, et al. Exploring the early workings of emerging clinical commissioning groups: final report. London: Policy Research Unit in Commissioning and the Healthcare System (PRUComm), 2012. http://blogs.Ishtm.ac.uk/prucomm/files/2012/ 11/Pathfinder-project-final-report-revised-v10-combined-post-peerreview-FINAL-correct-date_titles.pdf

6. Davies E, Martin S, Gershlick B. Under pressure: what the Commonwealth Fund's 2015 international survey of general practitioners means for the UK. The Health Foundation, 2016 http:// www.health.org.uk/publication/under-pressure

7. Holder H, Robertson R, Ross S, et al. Risk or reward? the changing role of CCGs in general practice. London: Kings Fund/Nuffield Trust, 2015.

8. England NHS. CCG 360 degree Stakeholder Survey 2016 overall report. Gateway Reference 05438: IPSOS Mori 2016.

9. McDermott I, Checkland K, Coleman A, et al. Engaging GPs in commissioning: realist evaluation of the early experiences of clinical commissioning groups in the English NHS. J Health Serv Res Policy 2017;22:4-11.

10. Checkland K, Coleman A, Perkins N, et al. Exploring the ongoing development and impact of clinical commissioning groups. London: Policy Research Unit in Commissioning and the Healthcare System (PRUComm), 2014.

11. Sibbald B, Bojke C, Gravelle H. National survey of job satisfaction and retirement intentions among general practitioners in England. BMJ 2003;326:22.

12. Robertson R, Holder H, Bennett L, et al; Primary care cocommissioning: a survey of members' views of their CCG and its role in primary care. London: Nuffield Trust/Kings Fund, 2015. http:// 
www.nuffieldtrust.org.uk/sites/files/nuffield/publication/ccg2015finalfor-web_0.pdf

13. Gibson J, Checkland $\mathrm{K}$, Coleman A, et al; Eighth National GP Worklife Survey. Manchester: Policy Research Unit in Commissioning and the Healthcare System Manchester Centre for Health Economics, University of Manchester, 2015.

14. Williams R. Using the margins command to estimate and interpret adjusted predictions and marginal effects. Stata J 2012;12:308-31.

15. StataCorp. Stata: release 14. College Station Texas: StataCorp, 2015.

16. England NHS. Next steps towards primary care co-commissioning. London: NHS England, 2014.

17. England NHS. Five year forward view. NHS England: Leeds, 2014.

18. Holder H, Robertson R, Naylor C. Has clinical commissioning found its voice? GP perspectives on their CCGs. London: Nuffield Trust/ Kings Fund, 2016. http://www.nuffieldtrust.org.uk/sites/files/nuffield/ publication/ccg_survey_2016_final_web_2.pdf
19. Drake, JE. Commissioning and GPs: to commit[tee] or not? Public Money \& Management 2016;36:121-8.

20. Coleman A, Checkland K, Harrison S, et al. Practice-based Commissioning: Theory,implementation and outcome. Final report. University of Manchester: National Primary Care Research and Development Centre, 2009.

21. NHS Commissioning Board. Towards establishment: creating responsive and accountable clinical commissioning groups, 2012.

22. NHS Commissioning Board. Clinical commissioning group governing body: Roles outlines, attributes and skills, 2012.

23. McKinstry B, Colthart I, Elliott K, et al. The feminization of the medical work force, implications for Scottish primary care: a survey of Scottish general practitioners. BMC Health Serv Res 2006;6:1-8.

24. Gravelle H, Hole AR. The work hours of GPs: survey of english GPs. Br J Gen Pract 2007;57:96-100. 